\title{
Trend Detection in Seasonal Inflows and the Influence on Energy Generation in Goleşti Hydropower Plant
}

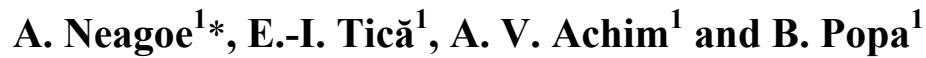 \\ ${ }^{1}$ University Politehnica of Bucharest, Dept. of Hydraulics, Hydraulic Machinery and Environmental \\ Engineering, Bucharest, Romania \\ *E-mail of corresponding author: angela.neagoe@upb.ro
}

\begin{abstract}
Among the multiple water uses, electricity generation is a factor strongly affected by alterations in the water cycle due to climate change. Long periods of drought followed by rainy periods lead to significant changes in the natural regimes of water flow in rivers. This paper aims to determine the long-term trends of seasonal inflows (spring, summer, autumn, winter) in Goleşti reservoir using daily data recorded over an 11-years period with the non-parametric Mann-Kendall test. The influence of tendency of increasing or decreasing was analyzed for the inflows in the Goleşti reservoir on the energy produced in associated hydropower plant.
\end{abstract}

Received 22 February 2021

Accepted 06 April 2021

Published 03 June 2021

Keywords: time series, seasonal trend, Student-t, Mann-Kendall test, hydropower generation.

\section{Introduction}

In Romania, most of the river courses are developed for electricity production, irrigation, water supply and flood protection, as well as for industrial water-use in some towns and villages. To be able to perform all these functions at the same time, must be created a system by which will be managed the required demands and, in many cases, a multi-purpose reservoir can be a relatively simple solution for this.

To analyze the trend detection in seasonal inflows and the influence on energy generation using a multi-purpose reservoir, in this study were considered data regarding Goleşti reservoir and associated hydropower plant.

As is known, energy generation of hydropower plants is directly influenced by the rivers discharges, having seasonal sinusoidal variation, corresponding to the four seasons.

The quantity of water into the river is mainly influenced by precipitations (liquid and solid), falling on the surface of the river basin from which the river collects its water. Other factors influencing rivers discharges are the evapotranspiration (which depends on air temperature, insolation, wind), the storage capacity of the catchment, the management of water resources, etc.

The effects of global climate change have led to extreme phenomena such as flooding in some areas and drought in others, large or sudden variations in temperatures, very high wind intensification in some regions, which have also influenced and modified the natural river flow regimes.

In the field of hydrology, many papers have taken a statistical approach for the long-term variation of

(C) The Author(s) 2021. Published by CIEES Association Press. This work is licensed under a Creative Commons Attribution-NonCommercialNoDerivs 4.0 Generic License. variables such as: precipitation, air temperature, water temperature, river flows, air humidity, etc. [1, 2, 3].

In Europe, in most countries, these types of analyses regarding the trend of flow rate increase or decrease have been carried out. For example, in [4] the authors observed an upward trend of river flows in southern and Central Germany and insignificant trend in Northern Germany. In [5] it was demonstrated that the river flows tend to decrease in the northern part of Poland. Following the study carried out in paper [6] it was concluded that clear decreasing trend in low flows throughout the northern half of Spain negatively influences the Atlantic and Mediterranean regions. For Italy, in paper [7], hydrological data of 23 flow gauges were considered for the analyses, to observe if the river flows show a decreasing trend in terms of global change. All the obtained parameters have indicated a substantial decrease of water resources. Some papers present the correlations between the trend of flows and precipitations [8, 9].

In Romania, the rise in global temperature (estimated at $0.5^{\circ} \mathrm{C}$ in the last century) has led to changes in the spatial and temporal distribution of the amount of rain and snow precipitation on the country's territory. The variations of the temperature using time series for winter (1922-1998) and for all seasons (1960-1998) in Romania were analysed from trend and shifts point of view using the Pettitt and Mann-Kendall in [10] and precipitation for period 1962-2006 in [11]. For the period 1976-2005, was made in [12] an analysis of the mean monthly streamflow applying the Mann-Kendall nonparametric test. The main result of the authors was that in the summer months there are decreasing trends and on the winter months the streamflow rate values have a positive trend. Therefore, the same results were also obtained in [13] for the period 1961-2009, where was made an analysis regarding hydroclimatic dynamics for Romanian drylands and aimed the tendency of the streamflow that is directly 
influenced by climate change. The climatic water deficit involves a streamflow reduction.

This paper presents the analysis of the trend detection in seasonal inflows in Goleşti multi-purpose reservoir and the influence on energy generation in the associated hydropower plant.

\section{The analysed time series}

The analysis focuses on the Golești reservoir and associated hydropower plant, using data from the period 2006-2016. The two analyzed variables consist of the daily average values of the inflows in the Golești reservoir and the daily energy generation in Golești hydropower plant. As the seasonal trend is being detected, both the inflows and the energy generation have been grouped into four series of values corresponding to the four seasons: the series Qsp contains all the daily inflows into the reservoir in the 3 months of spring (March, April, May) of all 11 years analyzed and Esp contains the daily values of energy produced during these periods (Fig. 1). Similarly, the Qsu and Esu strings were built from the flows and energies corresponding to the 3 months of summer (June, July, August). The Qau and Eau series were built for the autumn months and the Qwi and Ewi series being made up for the winter months (December, January, February).

The recorded values for the flows for the spring months, March (31 days), April (30 days) and May (31 days), were concatenated for the 11 years of analysis shall form the time series called $Q_{\text {spring }}$ which is represented in Figure 1 (a) and the values of energy produced in the Golești hydropower plant Figure 1 (b).

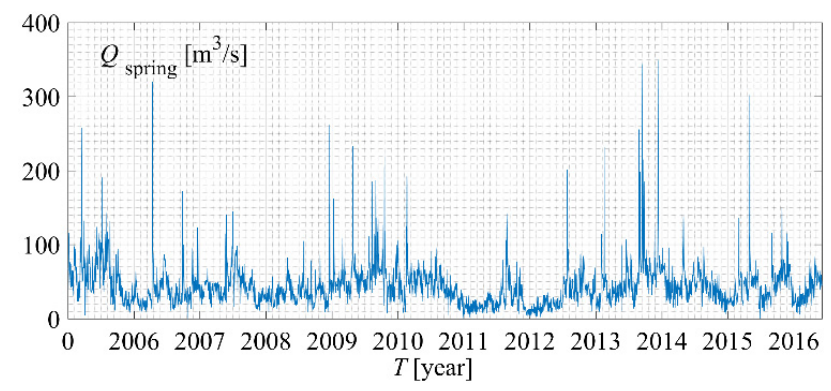

a)

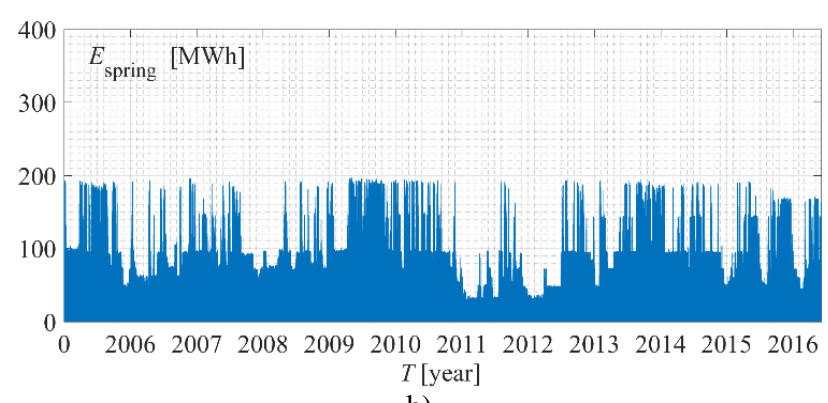

b)

Fig. 1. Spring daily inflow (a) and recorded energy generation (b) in the period 2006-2016.

The main characteristics of these time series are listed in Table 1 and Table 2.

From the analysis of the values in Tables 1 and 2, it can be observed that the average flows are higher in spring and autumn and correspondingly, the energy generation in hydropower plants is higher in spring and summer than during the rest of the year.

Table 1. Basic statistics of seasonal inflow series $\left[\mathrm{m}^{3} / \mathrm{s}\right]$.

\begin{tabular}{lcccc}
\hline $\begin{array}{l}\text { Reservoir } \\
\text { inflow }\end{array}$ & Average & $\begin{array}{c}\text { Standard } \\
\text { deviation }\end{array}$ & $\begin{array}{c}\text { Minimum } \\
\text { value }\end{array}$ & $\begin{array}{c}\text { Maximum } \\
\text { value }\end{array}$ \\
\hline Spring & 51.44 & 30.96 & 4.13 & 343.82 \\
Summer & 48.19 & 29.31 & 3.86 & 348.33 \\
Autumn & 35.66 & 24.03 & 0.45 & 301.78 \\
Winter & 39.85 & 21.80 & 0.16 & 233.39 \\
\hline
\end{tabular}

Table 2. Basic statistics of seasonal energy generation [MWh].

\begin{tabular}{lcccc}
\hline $\begin{array}{l}\text { Daily hydro- } \\
\text { electricity } \\
\text { produced }\end{array}$ & Average & $\begin{array}{c}\text { Standard } \\
\text { deviation }\end{array}$ & $\begin{array}{c}\text { Minimum } \\
\text { value }\end{array}$ & $\begin{array}{c}\text { Maximum } \\
\text { value }\end{array}$ \\
\hline Spring & 119.40 & 46.58 & 29.65 & 195.74 \\
Summer & 118.42 & 46.45 & 33.79 & 195.09 \\
Autumn & 94.79 & 47.96 & 8.55 & 196 \\
Winter & 98.10 & 43.51 & 17.73 & 196.83 \\
\hline
\end{tabular}

\section{Time series homogeneity tests}

\subsection{The student-t test}

In the method of statistical tests for trend detection, the original series is divided into two subseries of unequal numbers, having $n_{1}$ and $n_{2}$ components, respectively, such that $N=n_{1}+n_{2}$.

The homogeneity of the mean values of the two subseries shall be checked by means of the Student-t test. The t-test statistic [14] is defined as:

$t_{o b s}=\frac{\left|\bar{X}_{1}-\bar{X}_{2}\right|}{s_{p} \sqrt{\frac{1}{n_{1}}+\frac{1}{n_{2}}}}$,

where $s_{p}$ is the series variance, calculated as:

$s_{p}=\sqrt{\frac{n_{1} s_{1}^{2}+n_{2} s_{2}^{2}}{n_{1}+n_{2}-2}}$.

The null hypothesis $H_{0}: \mu_{1}=\mu_{2}$ (the averages of the two subsets are equal) is accepted if:

$\left|t_{o b s}\right|<t_{1-\frac{\alpha}{2}}$,

in which $t_{1-\frac{\alpha}{2}}$ is the distribution quantile $t$ with $n_{1}+n_{2}-2$ degree of freedom. The alternative hypothesis is $H_{1}: \mu_{1} \neq \mu_{2}$ (the averages of the two subsets are significantly different).

If $H_{0}$ is accepted at the level of significance $\alpha$, it can be allowed that the differences between the two averages are due by chance and the original series is homogeneous on average and it could be affirmed that the series don't have significant trend.

\subsection{The Mann-Kendall test}

This test is frequently used to detect monotone trends in a series of data such as hydrological or climatic dataset [15]. The null hypothesis is $H_{0}$ : the components of the time series shall be independent and uniformly distributed so that there is no trend in the analyzed data series. 
The alternative hypothesis is $H_{1}$ : the trend in the analyzed data series exists and it is significant.

To choose one of the two hypotheses, the following statistical value [16] is calculated as:

$$
S=\sum_{i=1}^{N-1} \sum_{j=i+1}^{N} \operatorname{sgn}\left(X_{j}-X_{i}\right) \text {, }
$$

where:

$$
\operatorname{sgn}(\theta)= \begin{cases}+1, & \text { if } \theta>0 \\ 0, & \text { if } \theta=0 . \\ -1, & \text { if } \theta<0\end{cases}
$$

Under the hypothesis of independent and randomly distributed random variables, the $S$ statistic is approximately normally distributed, with zero mean and variance as follows:

$$
\sigma^{2}=\frac{N(N-1)(2 N+5)}{18} \text {, }
$$

where $N$ is the number of set values.

In this case, the standardized $Z$ statistics follow a normal standardized distribution:

$$
Z=\left\{\begin{array}{l}
\frac{S-1}{\sigma} \text { if } S>0 \\
0 \quad \text { if }=0 \\
\frac{S+1}{\sigma} \text { if } S<0
\end{array} .\right.
$$

The null hypothesis that there is no trend is rejected when the absolute value of $Z$ is greater than the critical value $Z_{\alpha}$, at a chosen level of significance $\alpha$. An upward or downward trend is indicated by a positive or negative $Z$ statistics value.

\section{Results and discussion}

Table 3 shows the values obtained for the estimators applying the Student- $t$ test for mean trend testing for seasonal flow rate and table 4 for the daily average energy generation in hydropower plant Golești.

Table 3. Estimators with Student-t test for seasonal flow rate.

\begin{tabular}{lll}
\hline$Q$ & $t_{\text {obs }}$ & $t_{1-\alpha / 2}$ \\
\hline Spring & 1.056 & 1.962 \\
Summer & $\mathbf{5 . 4 2 6}$ & $\mathbf{1 . 9 6 2}$ \\
Autumn & 1.633 & 1.962 \\
Winter & $\mathbf{3 . 2 2 3}$ & $\mathbf{1 . 9 6 2}$ \\
\hline
\end{tabular}

Table 4. Estimators with Student-t test for the daily average energy generation.

\begin{tabular}{lcc}
\hline \multicolumn{1}{c}{$E$} & $t_{\text {obs }}$ & $t_{1-\alpha / 2}$ \\
\hline Spring & 2.133 & 1.962 \\
Summer & $\mathbf{7 . 1 7 0}$ & $\mathbf{1 . 9 6 2}$ \\
Autumn & 1.676 & 1.962 \\
Winter & $\mathbf{2 . 5 0 5}$ & $\mathbf{1 . 9 6 2}$ \\
\hline
\end{tabular}

After applying the Student- $t$ test, it can be can observed that there is a trend both for flows and for the energy produced during the summer and winter months. Tables 5 and 6 contain the estimator's values for the seasonal inflows and energy production obtained by Mann-Kendall test.
Observing the results from Tables 5 and 6 , it can be concluded that for the summer season, both in terms of flow rates and energy, there is a decreasing trend. Also, negative values of $Z$ for flow rate values show a decreasing trend in spring and summer, as can be seen from the linear regression equation found from the recorded values (Table 7).

Table 5. Mann-Kendall test's estimators for seasonal inflows series.

\begin{tabular}{lccc}
\hline Stream flow & $S$ & $Z$ & $Z_{\alpha}$ \\
\hline Spring & -919 & -0.085 & 1.64 \\
Summer & -81768 & $\mathbf{- 7 . 6 1}$ & $\mathbf{1 . 6 4}$ \\
Autumn & 29435 & $\mathbf{2 . 7 8 6}$ & $\mathbf{1 . 6 4}$ \\
Winter & 16033 & 1.543 & 1.64 \\
\hline
\end{tabular}

Table 6. Mann-Kendall test's estimators for energy generation series.

\begin{tabular}{lccc}
\hline Energy generation & $S$ & $Z$ & $Z_{\alpha}$ \\
\hline Spring & 37432 & $\mathbf{3 . 4 8}$ & $\mathbf{1 . 6 4}$ \\
Summer & -87124 & $\mathbf{- 8 . 1 1}$ & $\mathbf{1 . 6 4}$ \\
Autumn & -6201 & -0.58 & 1.64 \\
Winter & 16075 & 1.547 & 1.64 \\
\hline
\end{tabular}

\begin{tabular}{|c|c|c|}
\hline Season & $Q\left[\mathrm{~m}^{3} / \mathrm{s}\right]$ & $E[\mathrm{MWh}]$ \\
\hline Spring & $\left.Q_{\mathrm{sp}}=52.09-0.0013 \cdot t\right\rangle$ & $E_{\mathrm{sp}}=112.77+0.013 \cdot \mathrm{t}$ \\
\hline Summer & $\left.Q_{\mathrm{su}}=59.17-0.0217^{\prime} t\right\rangle$ & $\left.E_{\mathrm{su}}=137.53-0.03 \mathrm{t}\right\rangle$ \\
\hline Autumn & $Q_{\mathrm{au}}=32.704+0.0059^{\prime} t \nearrow$ & $\left.E_{\mathrm{au}}=95.87-0.0022 \mathrm{t}\right\rangle$ \\
\hline Winter & $Q_{\mathrm{wi}}=39.645+0.0004 t \lambda$ & $E_{\mathrm{wi}}=91.85+0.012 \mathrm{t} \nearrow$ \\
\hline
\end{tabular}

Table 7. Regression coefficient equations for stream flow and energy generation in Golești and the increasing $(\nearrow)$ or decreasing tendency $(\downarrow)$

From Figure 2 it can be observed that, except the year 2014 which was rainy, the trend over the last years analyzed was to decrease the streamflow rate values, while the energy produced on spring is oscillating slightly around the mean values.

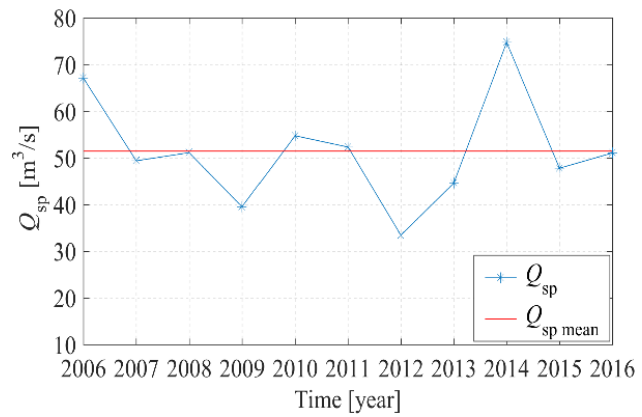

a)

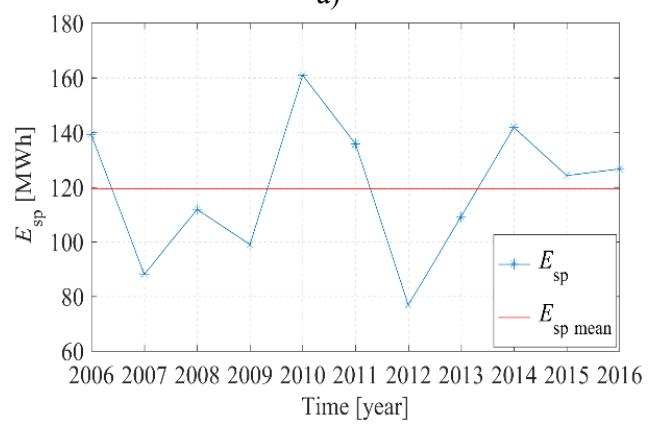

b) 
Fig. 2. Spring seasonal average flow rates (a) and seasonal average energies (b).

From Fig. 3 the decreasing trend in both the flows values and the energy generation during the summer period are observed, as shown by the two statistical tests (Student-t and Mann-Kendall).

It is also noted that between 2011 and 2016 in only one year (2014), the mean flows values and the energy generation exceeded the average values of the flows and the energy generation, respectively.

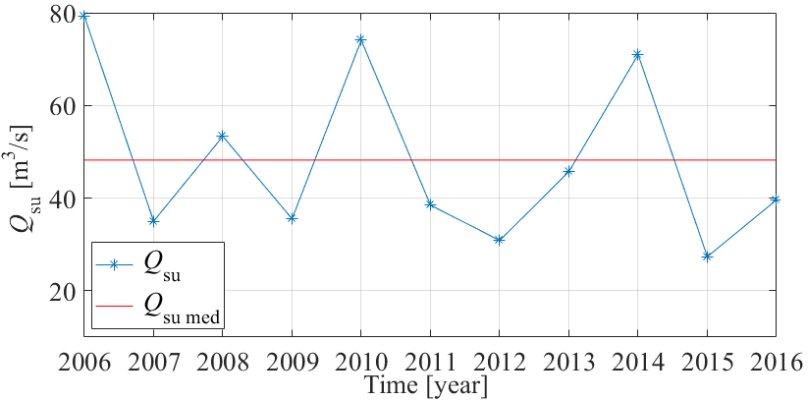

a)

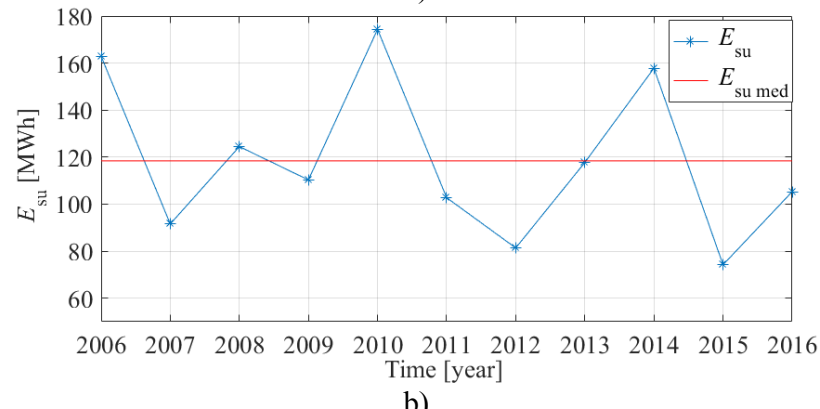

b)

Fig. 3. Summer seasonal average flow rates (a) and seasonal average energy generation (b).

Figure 4 presents autumn seasonal average flow rates and seasonal average energies.

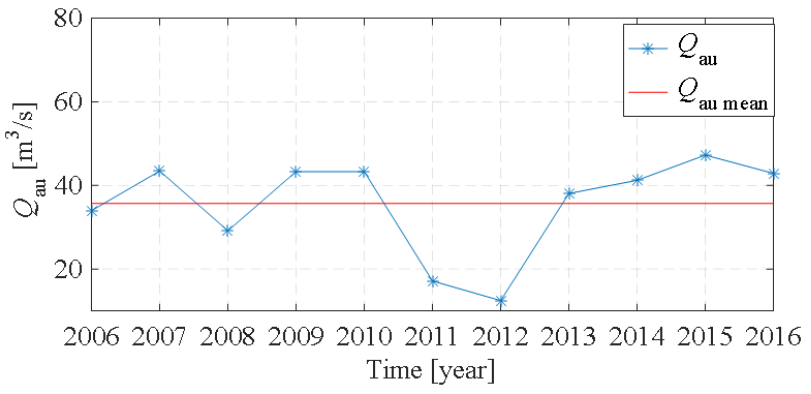

a)

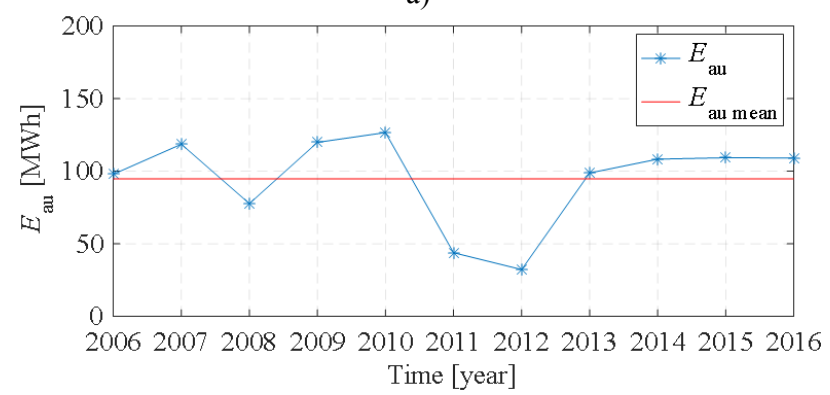

b)

Fig. 4. Autumn seasonal average flow rates (a) and seasonal average energies (b).
Although the Mann-Kendall test suggested a trend of increasing flows and decreasing energies produced in autumn, in accordance with the regression equations obtained, from Figure 4 it can be observed that the two series do not deviate from the average value, except for 2011 and 2012. For this season, the trend is insignificant.

Last figure, Fig. 5, presents values for winter seasonal flow rates and the variation of seasonal average energies. From this figure it can be observed that for winter months, when the mean streamflow rates value is lowest, the energy graph produced accurately follows the graph of all streamflow rates values in the reservoir.

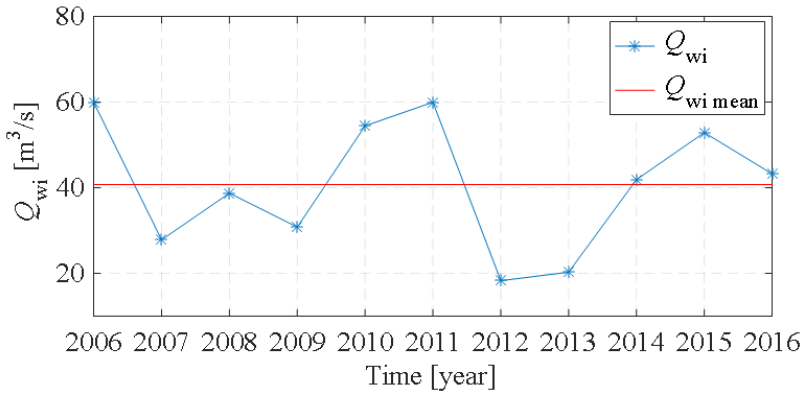

a)

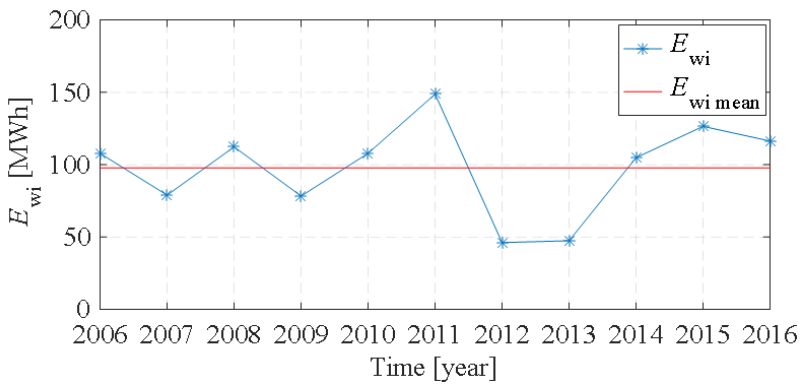

b)

Fig.5. Winter seasonal average flows (a) and seasonal average energy generation (b).

For this season, the Student-t test shows an increase in trend for inflows and energy generation but, from the coefficients of the linear regression it can be observed that the slope of this line is small, so that the tendencies are insignificant.

For better highlighting the results obtained after the application of the two tests, in all presented figures 2, 3, 4 and 5 were represented graphically the seasonal values corresponding to each year together with the seasonal average value calculated for eleven years of analysis.

\section{Conclusion}

In this paper it was made a statistical analysis in order to determine the trends of seasonal inflows (spring, summer, autumn, winter) in Goleşti reservoir using daily data recorded over an 11-years period using the nonparametric Mann-Kendall test.

In good agreement with other studies carried out for hydrological parameters in Romania, this paper shows a significant correlated decrease in summer flows and energy generation in Goleşti hydropower plant. For the other seasons, due to very small values of regression coefficients of time ( $\mathrm{t}$ ) the correlation between flows and energy generation is weak. 


\section{References}

[1] Longobardi, A. \& Villani, P. (2010). Trend analysis of annual and seasonal rainfall time series in the Mediterranean area", Int. J. Climatology, vol. 30, no. 10, 1538-1546. https://doi.org/10.1002/joc.2001

[2] Jaiswal, R. K., Lohani, A. K. \& Tiwari, H. L. (2015). Statistical Analysis for Change Detection and Trend Assessment in Climatological Parameters", Environ. Process. 2, 729-749. https://doi.org/10.1007/s40710-015-0105-3

[3] Birsan, M.-V., Zaharia, L., Chendes, V. \& Branescu, E. (2013) Seasonal trends in Romanian stream flow, Hydrological Processes, vol. 28, no. 15, 4496-4505, https://doi.org/ 10.1002/hyp.9961

[4] Bormann, H. \& Pinter, N. (2017). Trends in low flows of German rivers since 1950: comparability of different low-flow indicators and their spatial patterns, River Research and Applications, vol. 33, no. 7, 1191-1204. https://doi.org/ 10.1002/rra.3152

[5] Piniewski, M., Marcinkowski, P. \& Kundzewicz, Z. W. (2018). Trend detection in river flow indices in Poland, Acta Geophysica,vol. 66, 347-360. https://doi.org/10.1007/s11600018-0116-3

[6] Coch, A. \& Mediero, L. (2016). Trends in low flows in Spain in the period 1949-2009, Hydrological Sciences Journal, vol. 61, no. 3, 568-584. https://doi.org/10.1080/02626667. 2015.1081202

[7] Billi, P. \& Fazzini, M. (2017). Global change and river flow in Italy, Global and Planetary Change, vol. 155, 234-246. https://doi.org/10.1016/j.gloplacha.2017.07.008

[8] Uddin, M., Akter, S., Uddin, M.J. \& Diganta, M. (2018). Trend Analysis Variations and Relation Between Discharge and Rainfall: a Study on Kushiyara River, Journal of Environmental Science and Natural Resources, vol. 10, no. 2, 121-132. https://doi.org/10.3329/jesnr.v10i2.39025
[9] Abghari, H., Tabari, H. \& Talaee, P.H. (2013). River flow trends in the west of Iran during the past 40 years: Impact of precipitation variability, Global and Planetary Change, vol. 101, 52-60. https://doi.org/10.1016/j.gloplacha.2012.12.003

[10] Tomozeiu, R., Busuioc, A. \& Stefan, S. (2002). Changes in seasonal mean of maximum air temperature in Romania and their connection with large-scale circulation, International Journal of Climatology, vol. 22, no. 10, 1181-1196. https://doi.org/10.1002/joc.785

[11] Zaharia, L. \& Beltrando, G. (2009). Variabilité et tendances de la pluviométrie et des débits de crue dans la région de la courbure de l'arc carpatique (Roumanie), Geographia Technica, Numéro special, 471-476.

[12] Birsan, M.-V., Zaharia, L., Chendes, V. \& Branescu, E. (2012). Recent trends in streamflow in Romania (1976-2005), Romanian Reports in Physics, vol. 64, no. 1, 275-280.

[13] Prăvălie, R., Zaharia, L., Bandoc, G., Petrisor, A.-I., Ionuş, M. O. \& Mitof, I. (2016). Hydroclimatic dynamics in southwestern Romania drylands over the past 50 years, Journal of Earth System Science, vol. 125, 1255-1271. https://doi.org/10.1007/s12040-016-0730-x

[14] Popa, R. \& Neagoe, A. (2008). Elemente de statistică şi prelucrarea datelor (Elements of statistics and data processing), Printech Publishing house, Bucharest.

[15] Yue, S., Pilon, P. \& Cavadias, G. (2001). Power of the Mann-Kendall and Spearman's rho tests for detecting monotonic trends in hydrological series, Journal of Hydrology, vol. 259, no. 1-4, 254-271. https://doi.org/10.1016/S00221694(01)00594-7

[16] Kendall, M. G. (1962). Rank Correlation Methods, Hafner Publishing Company: New York. 